\title{
Neurocritical Care Training for the Neurosurgery Resident*
}

\author{
Paul E. Kaloostian ${ }^{1,2 \#}$, Jennifer Kim², Howard Yonas ${ }^{1}$ \\ ${ }^{1}$ Department of Neurosurgery, University of New Mexico Medical Center, Albuquerque, USA \\ ${ }^{2}$ Department of Neurosurgery, The Johns Hopkins Hospital, Baltimore, USA \\ Email: \#paulkaloostian@hotmail.com
}

Received February 7, 2013; revised March 8, 2013; accepted March 16, 2013

Copyright (C) 2013 Paul E. Kaloostian et al. This is an open access article distributed under the Creative Commons Attribution License, which permits unrestricted use, distribution, and reproduction in any medium, provided the original work is properly cited.

\begin{abstract}
Introduction: Recent data has associated favorable outcomes in patients who were treated in a "semi-closed" intensive care unit and attended to by a devoted team of neurointensivists as opposed to the neurosurgeons. This has led many to question the need for dedicated critical care education in the neurosurgical residency training program. Our aim was to determine what current neurosurgery residents and program directors/chairman thoughts were on NCC education in neurosurgical resident training, and to discuss possible methods to allow for collaboration between the NCC team and the neurosurgeons. Methods: Surveys were sent out electronically to all residency programs. Thirty-nine responses from junior residents, 36 responses from senior/chief residents, and eight responses from program directors/chairman were obtained. Results: No statistical difference between the majority responses of the different level residents and between program directors/chairman and combined resident responses. Conclusions: Clearly, neurosurgery residents of all levels and program directors/chairman value NCC education and see a valuable role for this knowledge in their future. Most residents, however, do not want to spend an additional year of fellowship training to become certified neurointensivists. We discuss the role of NCC education in residency training and possible solutions to allow collaboration between the NCC team and the neurosurgical team.
\end{abstract}

Keywords: Neurocritical Care; Neurosurgery Resident; Neurosurgery Survey; Neurointensivist

\section{Introduction}

Over the last decade, neurosurgical care has evolved into a multi-specialty, multi-modality collaboration. In the past, patient care was largely under the direction of the neurosurgery team, as residents and attendings would manage complex patients with multiple organ pathologies. The neurosurgery intensive care unit (NICU) ran as an "open” unit, allowing the admitting surgeon to remain the primary provider throughout the patient's stay, bringing in consult teams on a case-by-case basis. More recently, however, a "semi-closed" model has become more popular, in which the admitting physician transfers much of the patient care over to a subspecialized and highly trained group of neurointensivists (NI) [1].

Recent data has associated favorable outcomes in neurosurgical patients who were treated in a "semi-closed" ICU setting and attended to by a devoted team of NIS [2]. These NIs have been well-trained in a variety of inten-

\footnotetext{
*Acknowledgements/conflicts of interest: none.

${ }^{\#}$ Corresponding author.
}

sive care unit (ICU) procedures (such as tracheostomies, bronchoscopes, arterial lines, central lines, and percutaneous gastrostomies) and are knowledgeable about neurological pathology. They are also familiar with the unique physiologic considerations that must be taken into when managing brain and spinal cord-injured patients, and can act efficiently to prevent secondary insults in the postoperative or intensive care setting. This customized care has been shown to improve outcome and diminish hospital costs [1].

Despite these benefits, the semi-closed model also led to ambiguity regarding the roles of the neurosurgeon and NI in managing the critically ill neurosurgical patient. The result is often an imprecise or overlapping set of responsibilities, with each party working with or against the other in an effort to maintain longitudinal care. The purpose of this study was to understand how neurosurgery residents of all levels and program directors or chairmen throughout the United States felt about this shifting paradigm in patient care. Our goal was to identify a general consensus or any common themes in opin- 
ions regarding NICU care, NI versus neurosurgery involvement in the intensive care setting, and the existing versus optimal level of neurocritical care education in residency programs nationwide.

\section{Methods}

Surveys were sent out electronically to all residency programs in the United States. Responses from residents, program directors/chairman were collected and the results were tallied in blind fashion. Fisher exact test was performed to compare responses between junior and senior/chief residents, and between residents and program directors/chairman; a probability value of $<0.05$ was considered to be statistically significant. See Table 1 for the full questionnaire.

\section{Results}

The results of the questionnaire are summarized in Tables 2 and 3.

Thirty-nine responses from junior residents, 36 responses from senior/chief residents, and eight responses from program directors/chairman were obtained. No statistical difference ( $p<0.05$ ) was found between the yes/no response rate between the different-level residents, with two exceptions (Table 2). In response to the question "Would you spend an additional year for fellowship training in neurocritical care?” 27 (75\%) of the junior residents and $38(97 \%)$ of the senior residents, responded "no" ( $p=0.017)$. In response to the question "Should residents learn to perform tracheostomies/intubations/ external ventricular drains (EVD)/cerebral blood flow monitor(CBF)/LICOX placement/central lines/arterial lines (A Line)/dialysis/Swan Ganz catheter placement?” 24 (67\%) of the junior residents and 33 (85\%) of the senior residents responded “yes” ( $p=0.004)$.

No statistical difference was found between program directors/chairman and resident responses (Table 2). Additional comments and answers to open-ended questions regarding the value, need, and critique of critical care education are summarized in Table 3.

\section{Discussion}

Neurosurgical care has undergone significant changes over the last decade. The shifting paradigms of medical care have been especially apparent in the setting of the NICU. What was once a small specialized unit that catered to severely ill, ventilated patients has evolved into a large, multi-specialty and multi-modal entity in which not only neurosurgeons, but also anesthesiologists, neurologists and critical care specialists are charged with caring for an increasingly complex patient population [3]. The development of the neurointensive case sub-specialty was largely driven by high rates of medical errors and inadequate care nationwide; in response, physicians in medicine, anesthesiology and critical care began working together to provide highly specialized neurocritical care in a collaborative setting [4].

Since the introduction of the closed or semi-closed unit, the NI has emerged as a dominant figure in the non-operative care of critically ill neurosurgical patients. However, the role of the NI has been an area of interest and often contention by those in neurosurgery and other related fields. Additionally, there has been some reluctance to accept the semi-closed model for fear of entrusting the care of their patients to a NICU staff that may not have any neurosurgical expertise. It is understandable that the neurosurgeon would wish to participate in the care of their critically ill patient, even if a specialized neurocritical care team was available.

Despite these qualms, quality and efficacy studies have shown a clear improvement in outcomes following the implementation a specialized, NI-led NICU. In 2002, Pronovost et al. demonstrated that high intensity ICUs were associated with reduced hospital and ICU mortality and length of stay [5]. This association between intensivist-led care and improved patient outcome has also held up in NICU setting. A meta-analysis of 12 studies with 24,520 patients comparing outcomes before and after implementation of NIs demonstrated significantly lower mortality rates $(\mathrm{p}=0.01)$ and improved outcomes $(\mathrm{p}<$ 0.0001) in patients treated in specialized NICU's [1]. Varelas et al. compared outcomes of patients treated before and after implementation of NIs in the NICU and identified three critical factors that improved neurosurgical patient care: 1) implementing a dedicated NI in the NICU; 2) attention to detail; 3) better monitoring procedures. They also emphasized the crucial role of neurosurgery nurse whom they described as "the most important monitor" [6]. Further studies have shown that patients with traumatic brain injuries [7], non-traumatic intracerebral hemorrhage [8], and aneurysmal subarachnoid hemorrhage [9] are more likely to receive definitive treatment, experience better outcomes, shorter hospital stays [10] and have equal or lower mortality rates when treated by a dedicated multidisciplinary NICU team. These improved outcomes were associated with a positive impact on hospital savings and diminished overall hospital costs [9].

The successes of the semi-closed NICU system has raised questions in the neurosurgical education community, with educators and students asking: what role should residents play in this process? How much should they learn? Do they need to learn this information? How much neurocritical care education is too much and how much is too little? Such questions were the impetus for our study. Though neurointensivists have emerged as leaders in many NICU's to provide centralized, proto- 
Table 1. Survey questions.

\begin{tabular}{ll}
\hline & \multicolumn{1}{c}{ General questionnaire } \\
\hline 1) & Is neurocritical care training valuable for neurosurgery residents? \\
2) Is neurocritical care training valuable for you (resident)? \\
3) Should neurosurgery programs require neurocritical care training? \\
4) Is there a neurocritical care program in place at your training program? \\
5) Do you expect a neurosurgery residency program to have neurocritical care training experience? \\
6) Is a program without neurocritical care training a disadvantage to you or other residents? \\
7) Are hospitalist-guided ICUs without resident involvement a disadvantage? \\
8) Does your program have journal clubs/lectures regarding neurocritical care training? \\
9) Should there be a certified process for neurosurgery resident critical care training? \\
10) Should neurosurgery residents spend 1 year dedicated in the NICU? \\
\hline 11) Should residents learn to perform tracheostomies/intubations/external ventricular drains (EVD)/cerebral blood flow monitor (CBF)/LICOX \\
\hline 12) Would you spend an additional year for fellowship training in neurocritical care? \\
13) Do you want neurocritical care training in residency?
\end{tabular}

Additional questions for program directors/chairman only

15) Is neurocritical care education valuable in your daily work?

16) Is neurocritical care education valuable for resident education?

17) Should a neurosurgery residency require neurocritical care education?

col-driven therapy, neurosurgeons have a responsibility to become educated in the treatment of critically ill patients. Familiarity with the complications associated with this patient population ensures that the neurosurgeon will be able to provide the best care no only during but also after the acute event. Furthermore, the NICU provides a unique classroom in which one can better appreciate the nuances of neurologic disease processes. For instance, all participating specialties-neurology, neurosurgery, anesthesiology - have benefited from and continue to draw insights into the understanding of brain death and neurologic outcome [11].

Our results suggest that neurosurgical residents and program directors/chairman believe critical care education to be an essential component of their training programs. Most of the respondents agreed that they would be at a disadvantage if they did not receive critical care training, and that that they expected to be taught how to perform or place tracheostomies, intubations, EVDs, CBF monitors, LICOX, A lines, and dialysis/Swan Ganz catheters. On the other hand, a majority of the residents stated that they would not choose to spend an additional year for fellowship training in neurocritical care. Answers from the additional comments section of the survey reflect a belief that while neurosurgeon should be knowledgeable in the general management of critical care patients, the presence and dominance of NIs in the NICU renders a critical care fellowship unnecessary, except for those who want to become certified neurointensivists. A few respondents explicitly stated that a standardized exam and certification at the end of the critical care experience or residency program would be the most optimal way of ensuring that residents had had sufficient exposure to critical care medicine.

One factor that inhibits a standardized, nationwide change in the residency curriculum is the varying nature of neurosurgical practices across the country. Most neurosurgeons practice in community hospitals with a private practice or part-private/part-academic environment. There, neurocritical care teams can have significantly different skill sets and responsibilities in comparison to those in large high-volume academic medical centers. Thus, in smaller community hospitals, the neurosurgeon may well be appointed as the main care provider for critically ill patients, thereby necessitating adequate prior critical care training.

In spite of the varying levels of interest or motivations in critical care education, it is clear that the NICU provides an indispensable learning opportunity that enhances the understanding of the physiologic, pharma- 
Table 2. Survey responses.

\begin{tabular}{|c|c|c|c|c|c|}
\hline Survey questions & $\begin{array}{l}\text { Junior resident } \\
\text { response } \\
(\mathbf{n}=36)\end{array}$ & $\begin{array}{c}\text { Senior/chief } \\
\text { resident response } \\
(n=39)\end{array}$ & $\begin{array}{c}\text { P-value } \\
\text { (junior vs. senior } \\
\text { residents) }\end{array}$ & $\begin{array}{l}\text { prgrmdir/chair } \\
\text { response }(n=8)\end{array}$ & $\begin{array}{c}\text { P-value } \\
\text { (resident vs. } \\
\text { prgrm dir/chair) }\end{array}$ \\
\hline \multicolumn{6}{|l|}{ Want NCC training ${ }^{\dagger}$} \\
\hline Yes & 36 (100\%) & 39 (100\%) & $\mathrm{p}=1.000$ & $8(100 \%)$ & \\
\hline No & $0(0 \%)$ & $0(0 \%)$ & & $0(0 \%)$ & \\
\hline No response & $0(0 \%)$ & $0(0 \%)$ & & $0(0 \%)$ & \\
\hline \multicolumn{6}{|l|}{ Extra year $^{\dagger}$} \\
\hline Yes & $5(14 \%)$ & $0(0 \%)$ & $\mathrm{p}=0.017$ & & \\
\hline No & 27 (75\%) & 38 (97\%) & & & \\
\hline No response & $4(11 \%)$ & $1(2.6 \%)$ & & & \\
\hline \multicolumn{6}{|l|}{ Valuable for future $^{\dagger}$} \\
\hline Yes & 34 (97\%) & 37 (95\%) & $\mathrm{p}=1.000$ & & \\
\hline No & $0(0 \%)$ & $0(0 \%)$ & & & \\
\hline No response & $2(5.5 \%)$ & $2(5.1 \%)$ & & & \\
\hline \multicolumn{6}{|l|}{ Valuable for residents ${ }^{*}$} \\
\hline Yes & & & & $8(100 \%)$ & \\
\hline No & & & & $0(0 \%)$ & \\
\hline No response & & & & $0(0 \%)$ & \\
\hline \multicolumn{6}{|l|}{$\begin{array}{l}\text { Valuable for you } \\
\text { (prgrmdir/chair) }^{*}\end{array}$} \\
\hline Yes & & & & $8(100 \%)$ & \\
\hline No & & & & $0(0 \%)$ & \\
\hline No response & & & & $0(0 \%)$ & \\
\hline \multicolumn{6}{|l|}{$\begin{array}{l}\text { Nsurg residency } \\
\text { must have }^{*}\end{array}$} \\
\hline Yes & & & & $8(100 \%)$ & \\
\hline No & & & & $0(0 \%)$ & \\
\hline No response & & & & $0(0 \%)$ & \\
\hline \multicolumn{6}{|l|}{$\begin{array}{l}\text { Program in place at } \\
\text { your prgm }\end{array}$} \\
\hline Yes & & & & $8(100 \%)$ & \\
\hline No & & & & $0(0 \%)$ & \\
\hline No response & & & & $0(0 \%)$ & \\
\hline \multicolumn{6}{|l|}{$\begin{array}{l}\text { Expect NCC in } \\
\text { residency }\end{array}$} \\
\hline Yes & 36 (100\%) & 38 (97.5\%) & $\mathrm{p}=1.000$ & $8(100 \%)$ & $\mathrm{p}=1.000$ \\
\hline No & $0(0 \%)$ & $0(0 \%)$ & & $0(0 \%)$ & \\
\hline No response & $0(0 \%)$ & $1(2.6 \%)$ & & $0(0 \%)$ & \\
\hline \multicolumn{6}{|l|}{$\begin{array}{l}\text { Disadvantage if no } \\
\text { NCC }\end{array}$} \\
\hline Yes & $32(89 \%)$ & 33 (85\%) & $\mathrm{p}=1.000$ & $8(100 \%)$ & $\mathrm{p}=1.000$ \\
\hline No & $0(0 \%)$ & $0(0 \%)$ & & $0(0 \%)$ & \\
\hline No response & $4(11 \%)$ & $6(15 \%)$ & & $0(0 \%)$ & \\
\hline $\begin{array}{l}\text { Hospitalist guided ICU } \\
\text { w/o resident }\end{array}$ & & & & & \\
\hline
\end{tabular}




\section{Continued}

\begin{tabular}{|c|c|c|c|c|c|}
\hline Yes & 21 (58\%) & 24 (62\%) & $\mathrm{p}=1.000$ & $4(50 \%)$ & $\mathrm{p}=0.673$ \\
\hline No & 10 (28\%) & $10(26 \%)$ & & 3 (38\%) & \\
\hline No response & $5(14 \%)$ & $5(13 \%)$ & & $1(13 \%)$ & \\
\hline \multicolumn{6}{|c|}{ Available JC's/lect } \\
\hline Yes & $29(80 \%)$ & 27 (69\%) & $p=0.298$ & $8(100 \%)$ & $\mathrm{p}=0.188$ \\
\hline No & 7 (20\%) & 12 (31\%) & & $0(0 \%)$ & \\
\hline No response & $0(0 \%)$ & $0(0 \%)$ & & $0(0 \%)$ & \\
\hline \multicolumn{6}{|c|}{ Certified process? } \\
\hline Yes & $16(45 \%)$ & 15 (39\%) & $\mathrm{p}=0.610$ & $2(25 \%)$ & $\mathrm{p}=0.419$ \\
\hline No & 12 (33\%) & 15 (39\%) & & $4(50 \%)$ & \\
\hline No response & 8 (22\%) & 9 (23\%) & & 2 (25\%) & \\
\hline \multicolumn{6}{|l|}{1 year in NICU } \\
\hline Yes & $0(0 \%)$ & $0(0 \%)$ & $\mathrm{p}=1.000$ & $1(13 \%)$ & $\mathrm{p}=0.110$ \\
\hline No & 30 (83\%) & 35 (90\%) & & 7 (88\%) & \\
\hline No response & $6(17 \%)$ & $4(10 \%)$ & & $0(0 \%)$ & \\
\hline \multicolumn{6}{|l|}{ Tracheostomies } \\
\hline Yes & 12 (33\%) & $16(41 \%)$ & $\mathrm{p}=1.000$ & 3 (38\%) & $\mathrm{p}=1.000$ \\
\hline No & 17 (47\%) & 20 (51\%) & & 3 (38\%) & \\
\hline No response & 7 (19\%) & $3(7.7 \%)$ & & 2 (25\%) & \\
\hline \multicolumn{6}{|l|}{ Intubations } \\
\hline Yes & 26 (72\%) & 32 (82\%) & $\mathrm{p}=1.000$ & $6(75 \%)$ & $\mathrm{p}=0.108$ \\
\hline No & $0(0 \%)$ & $0(0 \%)$ & & $1(13 \%)$ & \\
\hline No response & $10(28 \%)$ & 7 (18\%) & & $1(13 \%)$ & \\
\hline \multicolumn{6}{|l|}{ EVD/CBF/Licox } \\
\hline Yes & 33 (92\%) & 36 (92\%) & $\mathrm{p}=1.000$ & 7 (88\%) & $p=0.104$ \\
\hline No & $0(0 \%)$ & $0(0 \%)$ & & $1(13 \%)$ & \\
\hline No response & 3 (8.3\%) & $3(7.7 \%)$ & & $0(0 \%)$ & \\
\hline \multicolumn{6}{|l|}{ G tubes } \\
\hline Yes & $0(0 \%)$ & $0(0 \%)$ & $\mathrm{p}=1.000$ & $1(13 \%)$ & $\mathrm{p}=0.094$ \\
\hline No & 27 (75\%) & 31 (79\%) & & $5(63 \%)$ & \\
\hline No response & $9(25 \%$ & 8 (21\%) & & 2 (25\%) & \\
\hline \multicolumn{6}{|l|}{ CVC } \\
\hline Yes & 35 (97\%) & 39 (100\%) & $\mathrm{p}=1.000$ & 7 (88\%) & $\mathrm{p}=1.000$ \\
\hline No & $0(0 \%)$ & $0(0 \%)$ & & $0(0 \%)$ & \\
\hline No response & 1 (3.8\%) & $0(0 \%)$ & & $1(13 \%)$ & \\
\hline \multicolumn{6}{|l|}{ A lines } \\
\hline Yes & 36 (100\%) & 38 (97\%) & $\mathrm{p}=1.000$ & 7 (88\%) & $\mathrm{p}=1.000$ \\
\hline No & $0(0 \%)$ & $0(0 \%)$ & & $0(0 \%)$ & \\
\hline No response & $0(0 \%)$ & $1(2.6 \%)$ & & $1(13 \%)$ & \\
\hline \multicolumn{6}{|l|}{ CVVHD } \\
\hline Yes & $6(28 \%)$ & $6(15 \%)$ & $\mathrm{p}=0.530$ & 5 (63\%) & $\mathrm{p}=0.008$ \\
\hline
\end{tabular}




\section{Continued}

\begin{tabular}{|c|c|c|c|c|c|}
\hline No & 20 (56\%) & 31 (80\%) & & $2(25 \%)$ & \\
\hline No response & 10 (28\%) & 2 (5.1\%) & & $1(13 \%)$ & \\
\hline \multicolumn{6}{|l|}{ Dialysis } \\
\hline Yes & 7 (19\%) & $0(0 \%)$ & $\mathrm{p}=0.004$ & $0(0 \%)$ & $\mathrm{p}=1.000$ \\
\hline No & 24 (67\%) & 33 (85\%) & & $6(75 \%)$ & \\
\hline No response & 5 (14\%) & $6(15 \%)$ & & 2 (25\%) & \\
\hline \multicolumn{6}{|l|}{ Swan-Ganz } \\
\hline Yes & 14 (39\%) & 21 (54\%) & $\mathrm{p}=0.456$ & $4(50 \%)$ & $\mathrm{p}=1.000$ \\
\hline No & 14 (39\%) & 14 (36\%) & & 3 (38\%) & \\
\hline No response & 8 (22\%) & $4(10 \%)$ & & 1 (13\%) & \\
\hline
\end{tabular}

'Questions for residents only. ${ }^{*}$ Questions for program directors/chairs only.

Table 3. Additional comments.

\section{RESIDENT COMMENTS:}

What aspects do you consider important? (i.e. CVC placement, A-line placement, critical care thinking skills, etc.)

Technical skills

- Critical care management skills \& minor procedures

- Management of Neuro ICU patients-pre and post-op, A-line and TLC placement (in emergency settings), nutrition, timing of tracheostomies/percutaneous gastrostomies

- Arterial and venous access, basic ventilator management, basic critical care strategies

- Thinking skills

- Critical Care thinking skills, in the event of practicing in a location with poor ICU staff

- Mostly critical care thinking and decision making is of the most importance. Placing lines comes just by being in the hospital for 7 years!

- Understanding of pathophysiology in critically ill neurotrauma and cerebrovascular patients

- Managing ICU patient's needs or interacting with ICU; do not wish to run ICU

- Critical care decision making in reference to neurosurgical issues

- Other

- Good for residents that will go into cranial work because you have to learn to manage your patients

- Probably not good for spine

What factors do you think impede current neurosurgical resident critical care education?

Time

- Time demands and the ease of letting an ICU team deal with non-neurological issues

- Inefficient ICU workflows, including poorly implemented computerized order systems, work hour regulations, high patient loads

- Time, increasing segregation of NICU care to neurologists

- 80-hour work week: most residency time used in the OR's/clinics

- Amount of time available to focus on it

- Time, emphasis of importance on the education, skilled critical care educators

- Work hours, decreased ICU rotations due to decreased time on general surgery

- Dedicated Neuro ICU staff and fellows impede resident education, no question. Without them, however, this necessitates interns to be present to manage the ICU's day to day ins and outs (vent weans, for example) while residents operate

- $\quad$ Service duties and need for residents in operating room

- Time crunch, closed units

- Division of labor/responsibility

- Excessive emphasis on surgical experience yet not enough importance on critical care

- Other clinical responsibilities and neuro critical care attendings

- Willingness of surgeons to defer critical care

- Neurocritical care commonly under Neurology leadership and control

- Neurocritical care practitioners not collaborative with neurosurgeons, neurosurgeons completely uninterested in critical care

- Mandated CC teams managing most neurocritical patients in the neuro ICUs

- Neurocritical care teams led by neurologists 


\section{Continued}

- Change in paradigm for intern year-now largely infolded to neurosurgery service with little interaction on ICU services

- Other

- They want to go into spine to make money

- I feel my training in neurocritical care is adequate for my needs

- "Education" is too broad of a term; I am in favor of critical care experience (i.e. ICU rotations), but a dedicated amount of time to critical care is not of benefit in my mind

\section{What factors should be included in this process (journal clubs, etc.)?}

Additional training

- Journal clubs, minimum of practice of CVC, arterial lines, and rotations devoted to neurocritical care

- Journal clubs, lectures, proctoring procedures (not just lines, but rather bronchoscopies and perch tracheostomies etc.), and then a written test

- Just passing the same test as other intensivists

- Formal certification

- Perhaps an infolded fellowship; board exam etc.

- The completion of a neurosurgical residency sufficient for qualification

- Just as we have a certification to operate, there should also be a fellowship training certification to care full-time for ICU needs

- A longitudinal curriculum outlined by the American Board of Neurological Surgery (ABNS) with an optional exam for certification at or near the end of training

What procedures should neurosurgery residents be comfortable within their critical care training? Procedures

- Central line and A-line placement, chest tube placement, intubation

- Basic ventilator management, management of hemodynamics of systemically ill patients

- EVD placement, emergency tracheostomies

- Percutaneous tracheostomies, bronchs, lines

- Ventriculostomy, ICP monitor, bedside drains, lines (if they wish to engage in critical care medicine as the sole provider)

- Arterial line, central venous access-jugular, subclavian, femoral, chest tube insertion, all intracranial pressure monitoring devices, EVD

- They should have placed CVCs but not necessarily be proficient; proficient in placement of arterial lines; basic ventilator management

- Other

- A year is excessive, our program has 6 months which seems sufficient

\section{CHAIRMAN/PROGRAM DIRECTORS COMMENTS:}

\section{Please list what mechanisms exist in your programs?}

Dedicated rotations

- NCC conferences weekly, NCC rotation

- Formal rotations on trauma critical care and general critical care teams

- Specific rotations without neurointensivist

- 2 to 3 months rotations in postgraduate year 1 and 16 months oversight rotation in PGY6

- Specific rotation in NSY1 year; daily interaction with critical care personnel in our ICU

- Continuity of care

- They round daily with the pulmonology or anesthesia attendings

- Rotations in critical care, ongoing education at journal club, continuous management of these patients

\section{What factors do you think impede current Neurosurgical resident critical care education?}

\section{Human resources}

- Lack of neuro-intensivists or other "neuro-savvy" intensivists to train residents in neuro-critical care time

- Misapplication of physician extenders, and divestment of ICU care to other services

- Division of labor/responsibility

- Control of NICU by hospital/non-neurosurgeons

- Use of non-neuro critical care to staff ICUs; Hospitals unwilling to recognize this as an important component of neurosurgery

- Other

- Lack of level I trauma, or cerebrovascular diseases

What factors should be included in this process (journal clubs, etc.)?

- Formal rotations

- ABNS certificate that includes neurocritical care 
cologic, microbiologic, and pathologic features of the neurosurgical patient. The experience also teaches the neurosurgeon how to develop a systematic approach and to work cooperatively with multidisciplinary team, and especially with the neurointensivists. The skills acquired from this experience, such as risk assessment and optimization, can only strengthen the curriculum, and further ensure the safety of these patients [12].

Ultimately, collaboration between the NCC team and the neurosurgical team-including residents at all levels-is needed to optimize both patient care and clinical education. Factors that can facilitate this collaboration include standardized rounding times where the neurosurgeons and NCC team meet to discuss the plans for the day, having a resident member of the neurosurgical team involved in rounds with the NCC team, allowing NCC team members into the operating room to observe neurosurgical procedures, weekly or monthly lectures from the NCC team on various topics related to critical care, and neurosurgical presentations by residents detailing important neurosurgical considerations to the entire NCC team. These strategies may help create a more collaborative environment in the NICU, which, in turn, will allow for the best possible patient care as well as a valuable learning experience for the neurosurgery residents.

Limitations of our study begin with the low power due to the few responses from residents and program directors nationwide. However, this is the best data in the neurosurgery literature thus far. Common themes and opinions come through clearly in the survey responses. This is the first study attempting to document this problem in neurosurgery resident education and undoubtedly a larger study, perhaps with the American Association of Neurological Surgeons and Congress of Neurological Surgeons, in accordance with the Senior Neurosurgical Society, needs to be done to confirm our initial results.

\section{Conclusion}

Our study demonstrates that neurosurgery residents of all levels and program directors/chairman value NCC education and see a valuable role for this knowledge in their future. Most residents however, express disinterest in an additional year of fellowship training to become certified neurointensivists. Likewise, the majority of program directors/chairman who were responded to the survey agrees that a year solely dedicated to NCC is not warranted. A variety of procedures such as intracranial monitoring devices, arterial lines, intubations, and central lines are clearly valued by neurosurgery residents as part of the requisite neurosurgical repertoire. Perhaps a shift in current standard neurosurgery resident training to include a focused 3 - 6 months rotation on the ICU service working as a team with the hospitalists may be an optimal educational experience. Additionally, a standardized neurocritical care examination (either written or oral) for all residents could be implemented to allow neurosurgery residents to practice neurocritical care in the future, should they so desire. These program additions would allow neurosurgeons to better tailor their education according to their interest or expected involvement in the critical care setting. Finally, we discuss certain key factors that may help in the collaborative process between the NCC team and the neurosurgical team.

\section{REFERENCES}

[1] A. H. Kramer and D. A. Zygun, "Do Neurocritical Care Units Save Lives? Measuring the Impact of Specialized ICUs,” Neurocritical Care, Vol. 14, No. 3, 2011, pp. 329333. doi:10.1007/s12028-011-9530-y

[2] T. P. Bleck, "The Impact of Specialized Neurocritical Care," Journal of Neurosurgery, Vol. 104, No. 5, 2006, pp. 709-710, Discussion 710 . doi:10.3171/jns.2006.104.5.709

[3] E. F. Wijdicks, W. R. Worden, A. Miers and D. G. Piepgras, "The Early Days of the Neurosciences Intensive Care Unit,” Mayo Clinic Proceedings, Vol. 86, No. 9, 2011, 903-906. doi:10.4065/mcp.2010.0815

[4] J. Gasperino, “The Leapfrog Initiative for Intensive Care Unit Physician Staffing and Its Impact on Intensive Care Unit Performance: A Narrative Review," Health Policy, Vol. 102, No. 2, 2011, pp. 223-228. doi:10.1016/j.healthpol.2011.02.005

[5] P. J. Pronovost, D. C. Angus, T. Dorman, K. A. Robinson, T. T. Dremsizov and T. L. Young, "Physician Staffing Patterns and Clinical Outcomes in Critically Ill Patients: A Systematic Review," The Journal of the American Medical Association, Vol. 288, No. 7, 2002, pp. 2151-2162. doi:10.1001/jama.288.17.2151

[6] P. N. Varelas, D. Eastwood, H. J. Yun, et al., "Impact of a Neurointensivist on Outcomes in Patients with Head Trauma Treated in a Neurosciences Intensive Care Unit," Journal of Neurosurgery, Vol. 104, No. 5, 2006, pp. 713719. doi:10.3171/jns.2006.104.5.713

[7] H. C. Patel, D. K. Menon, S. Tebbs, R. Hawker, P. J. Hutchinson and P. J. Kirkpatrick, "Specialist Neurocritical Care and Outcome from Head Injury,” Intensive Care Medicine, Vol. 28, No. 5, 2002, pp. 547-553. doi:10.1007/s00134-002-1235-4

[8] M. A. Mirski, C. W. Chang and R. Cowan, "Impact of a Neuroscience Intensive Care Unit on Neurosurgical Patient Outcomes and Cost of Care: Evidence-Based Support for an Intensivist-Directed Specialty ICU Model of Care,” Journal of Neurosurgical Anesthesiology, Vol. 13, No. 2, 2001, pp. 83-92. doi:10.1097/00008506-200104000-00004

[9] O. Samuels, A. Webb, S. Culler, K. Martin and D. Barrow, "Impact of a Dedicated Neurocritical Care Team in Treating Patients with Aneurysmal Subarachnoid Hemorrhage," Neurocritical Care, Vol. 14, No. 3, 2011, pp. 334-340. doi:10.1007/s12028-011-9505-Z

[10] J. I. Suarez, O. O. Zaidat, M. F. Suri, et al., "Length of 
Stay and Mortality in Neurocritically Ill Patients: Impact of a Specialized Neurocritical Care Team," Critical Care Medicine, Vol. 32, No. 11, 2004, pp. 2311-2317.

[11] A. H. Ropper, S. K. Kennedy and N. T. Zervas, "Neurological and Neurosurgical Intensive Care,” University Park Press, Baltimore, 2004.

\section{Abbreviations}

EVD: extraventricular drain;

CBF: cerebral blood flow;

CVVHD: continuous veno-venous hemodialysis;

ICU: intensive care unit;

NCC: neurocritical care;

NICU: neurosurgery intensive care unit;

Nsurg: neurosurgery;

Prgrmdir: program director.
[12] E. A. Pereira, H. Madder, J. Millo and C. F. Kearn, "Neurosciences Intensive Care Medicine in Initial Neurosurgical Training," British Journal of Neurosurgery, Vol. 23, No. 2, 2009, pp. 193-196. doi:10.1080/02688690802512841 